\title{
Geodynamics of Central Armenia Based on the Results of Hydrogeochemical Monitoring
}

\author{
Romela Artavazd Pashayan ${ }^{1}$, John Kostik Karapetyan ${ }^{1}$, Levon Vardan Harutyunyan ${ }^{2}$ \\ ${ }^{1}$ Alexander Nazarov Institute of Geophysics and Engineering Seismology of National Academy of Sciences of Armenia, Gyumri, Armenia \\ ${ }^{2}$ Institute of General and Inorganic Chemistry of National Academy of Sciences of Armenia, Yerevan, Armenia
}

\section{Email address:}

romellapashayan@sci.am (R. A. Pashayan), iges@sci.am (J. K. Karapetyan), levonharutyunyan25@rambler.ru (L. V. Harutyunyan)

\section{To cite this article:}

Romela Artavazd Pashayan, John Kostik Karapetyan, Levon Vardan Harutyunyan. Geodynamics of Central Armenia Based on the Results of Hydrogeochemical Monitoring. American Journal of Mechanics and Applications. Vol. 8, No. 3, 2020, pp. 40-46.

doi: $10.11648 /$ j.ajma.20200803.12

Received: November 9, 2020; Accepted: November 27, 2020; Published: December 31, 2020

\begin{abstract}
Method for geophysical monitoring of the earth's crust has been introduced since 2000 aiming to study the earth's crust of Central Armenia. The method allows to track modern geodynamic processes of the region. The nature of time-space distribution of hydrogeodeformation processes of Central Armenia has been studied. The nature of space-time distribution of geodynamic intensity is determined. Anomalies of components of chemical composition of water have been recorded on stressstrain areas of Earth's crust. Types of seismotectonic deformation have been determined. The present work introduces the hydrogeochemical method of studying the geodynamic processes of the Earth's crust of Armenia. The method is based on hydrogeochemical observations of the chemical composition of mineral waters and their comparison with seismicity. The objective of the hydro geochemical method is to identify hydrogeochemical effects which mainly occur in the changes of macro-component and gas composition of waters related to geodynamic movements of the Earth's crust. The results of the applicaiton of the hydrogeochemical method in the central part of the region, confirmed the connection of the parameters of seismic events variations with the chemical composition of groundwater, as well as carbon dioxide $\left(\mathrm{CO}_{2}\right)$ dissolved in water. Stressed areas of the Earth's crust are observed according to the anomalies of components of chemical composition of water. Types of seismotectonic deformation are determined. Geochemical anomalies are most clearly observed in the macrocomponent composition of mineral water and gases. Seismic events are preceded by geochemical anomalies of components of water composition in relation to background values in percentage ratio. The hydrogeochemical method, combined with other methods, can serve as a reliable precursor to earthquakes and other geodynamic processes of the Earth's crust. The role of the hydrogeochemical method is also effective for short-term and operational prediction of tectonic movements of the Earth's crust (earthquakes, in particular).
\end{abstract}

Keywords: Deformation, Seismicity, Earthquake, Dispersion, Correlation, Hydrogeochemistry, Geodynamics

\section{Introduction}

Armenia is rich in mineral water deposits, which are distributed throughout the region. Mineral water has hydrocarbonate, hydrocarbonate-chloride, sodium and chloride-sodium chemical composition. Mineral water are generally confined to deep tectonic faults. This allows to observe tectonic stresses which lead to local and remote earthquakes. The impact of earthquakes on the mineral water has been known for a long time. It been specifically stated in hydrogeological literature by Isnau, G. Kissin [1]. Hydrogeologist Anatoli, L. Ananyan and others [2] have also highlighted the influence of earthquakes on the mineral water of Arzni resort during the period between 1968-1976. As a result of the work carried out, they revealed a change in the mineralization of the groundwater of the Arzni resort under the influence of seismic tremors. In particular, a sharp increase in the mineralization of the mineral water of Arzni resort after the Turkish earthquake of 1976 (24.11 197-6 $\mathrm{M}=7.6$ ) was registered.

The influence of the Spitak earthquake (07.12.1998, $\mathrm{M}=7.0$ ) on the mineral water deposits of Armenia is reflected 
in the work of V. I. Ihumnov, Z. G. Stepanyan [3], who monitored the mineral springs after the earthquake and also noted an increase in the mineralization of the mineral water of the Arzni resort. Direct methods of studying geodynamic changes include geophysical methods, seismics, hydrogeodynamics, hydrogeochemistry.

Monitoring observations of the level of underground water were carried out on the tectonically active areas of Armenia. Detailed study of change forming factors made it possible to identify hydrogeodynamic effects caused by the influence of modern tectonic deformations.

The study of hydrogeodynamic effects of the change of stress-strain state of the enviornement as indicators of modern geodynamic processes [4] and the study of the chemical composition of underground water and the dissolved gases has huge theoretical and practical importance. Geochemical methods help to reconstruct the intensity of the Earth's crust and to record changes in its state over short periods of time.

The processes of geological environment deformation have direct influence on the chemical composition of underground water [5]. The values of geochemical components of water are indicators of geodynamic processes of the Earth's crust. The monitoring of the mineral water of central Armenia was directed towards the study and identification of hydrogeochemical effects preceding earthquakes and other geodynamic processes of the Earth's crust.

The aim of the study was the assessment of the stressstrain state of the Earth's crust of central Armenia, the locations of hydrogeochemical observation points, and the calculation of the Lode-Nadai coefficient, which characterizes the type of seismotectonic deformation. The identification of background values of parameters of chemical composition of water and determination of abnormal values of chemical elements of water of each observation point from parameters of the occurred earthquakes.

\section{Materials and Method}

Regular hydrogeochemical observations are carried out at observation stations I-IV (observation station I - Surenavan mineral water, observation station II - Vedi mineral water, observation station III - Bjni and observation station IVArzni) located along the main faults near common allCaucasian strike and being the main seismogenic structures in the territory of central Armenia.

StationsI and II are timed to the fledging of the structures of Yerevan deep fault, stationIII is timed to the intersection of Bzhni and Hrazdan faults, station IV is structurally timed to the middle part of Hrazdan cavity which has tectonic origin. Characteristic feature of mineral water is a high concentration of carbon dioxide, and sodium bicarbonate prevails in chemical composition of deep-seated water [6]. Increased concentration of gas is the cause of the movement of mineral water to the near-surface zone. On the one hand there is the occurrence of gas lift, and on the other hand, a significant amount of travertine is released in water-bearing fractures and on the surface. In the above listed hydrogeochemical stations, observations are carried out on self-draining borholes. Regular hydrogeochemical observations include a one-time sampling from each observation station and further chemical macrocomponent analysis of the water composition with the release of the amount of carbon dioxide dissolved in water under laboratory conditions. There are long time series of chemical components of water composition from each hydrochemical observation station [7]. Method of statistical processing of observation data is applied taking into account the geological and local climatic conditions of the places of formation of mineral water deposits.

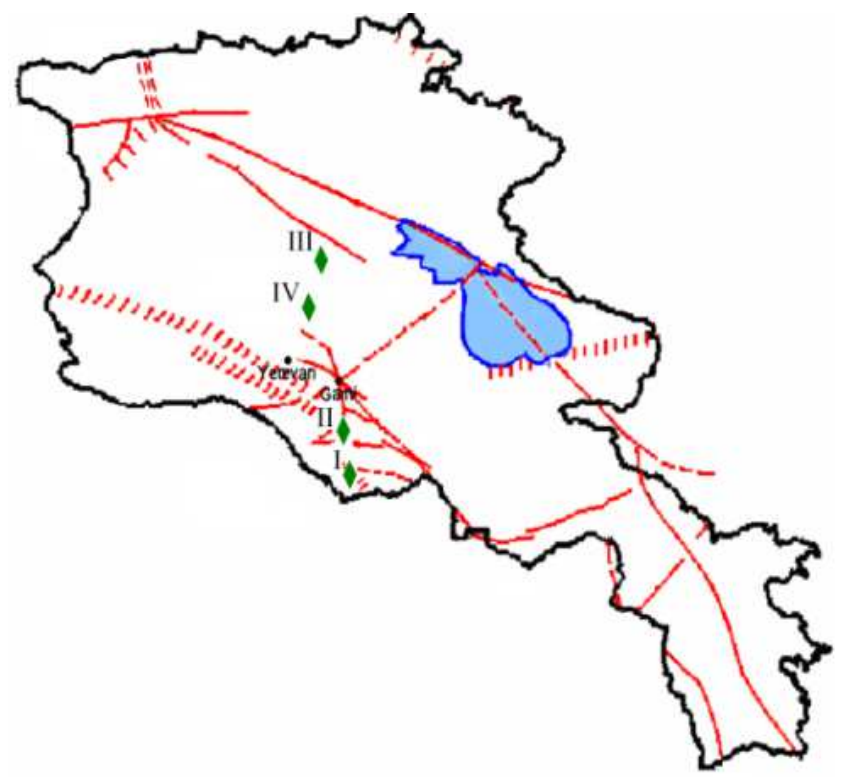

Figure 1. Map of Armenia with hydrogeochemical observation stations (IIV).

Method of calculating the abnormal values of concentration of chemical elements of water from their background value includes the subtraction of the linear trend and seasonal variations from the time series of chemical elements of the composition of water in boreholes, calculation of the mean square value of the concentration of chemical elements in time, calculation of the magnitude and dispersion of coefficient, and correlation with seismicity [8]. According to the hydrochemical observation stations (Figure 1), the seasonal course of changes in the water level is observed in borehole - I. (Figure 2); on the other mineral springs the effect of precipitation on the water level is not observed.

In the past five years, there has been a trend towards the decrease in the total mineralization of mineral water of the observation stations IV, III, II and a trend towards the increase in the total mineralization of water in station I. To monitor the geodynamics of the central part of Armenia, hydrogeochemical method has been applied, which is based on registration of abnormal changes in the chemical composition of mineral water in the period preceding the tectonic movements of the Earth's crust [9]. At the beginning, 
changes in the macrocomponent composition and the gas component $\mathrm{CO}_{2}$ of mineral water has been studied. The analysis of the data collected through regular observations for a number of years has made it possible to reduce the number of determinants. $\mathrm{CO}_{2}$ gas component of deep origin as well as $\mathrm{Mg}^{2+}, \mathrm{CL}^{-}, \mathrm{SO}_{2}{ }^{-4}, \mathrm{HCO}^{-3}$ and total mineralization value has been identified as the most informative. The connection of observation stations (mineral water boreholes I-IV) to deep tectonic faults increases the informative character of the observations. The study of the correlation between the parameters of seismic and geochemical fields allows us to identify the anomalies of geochemical components in connection with the earthquakes [10]. Consequently, we have considered catalogues of earthquakes (seismic data were received from the NSSP of the Ministry of Emergency Situations of the Republic of Armenia). Earthquakes with M> 2.0 with hypocentres have been selected (Figure 3) from the catalogue of earthquakes that occurred during 2014-2015.
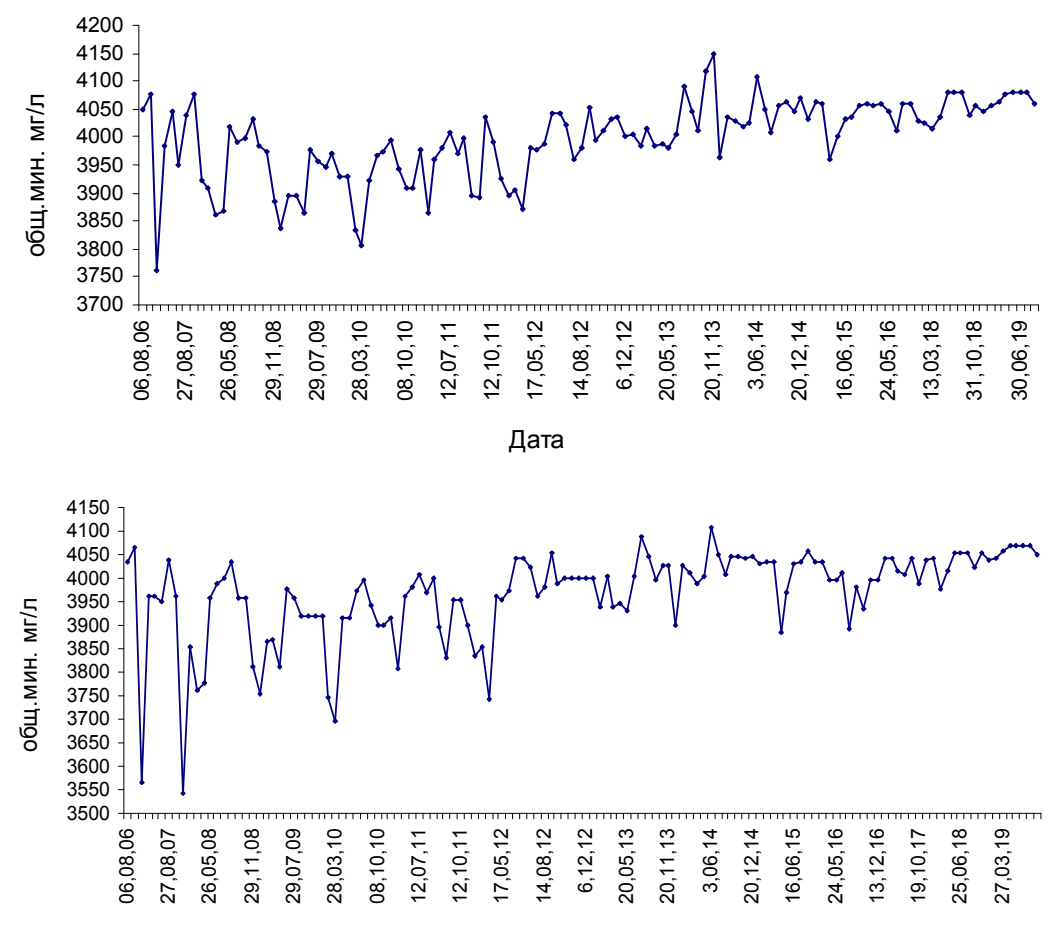

Дата

Figure 2. First graph of changes in rpm in the water of №I borehole; second graph obtained by subtracting seasonal variations from the initial series.

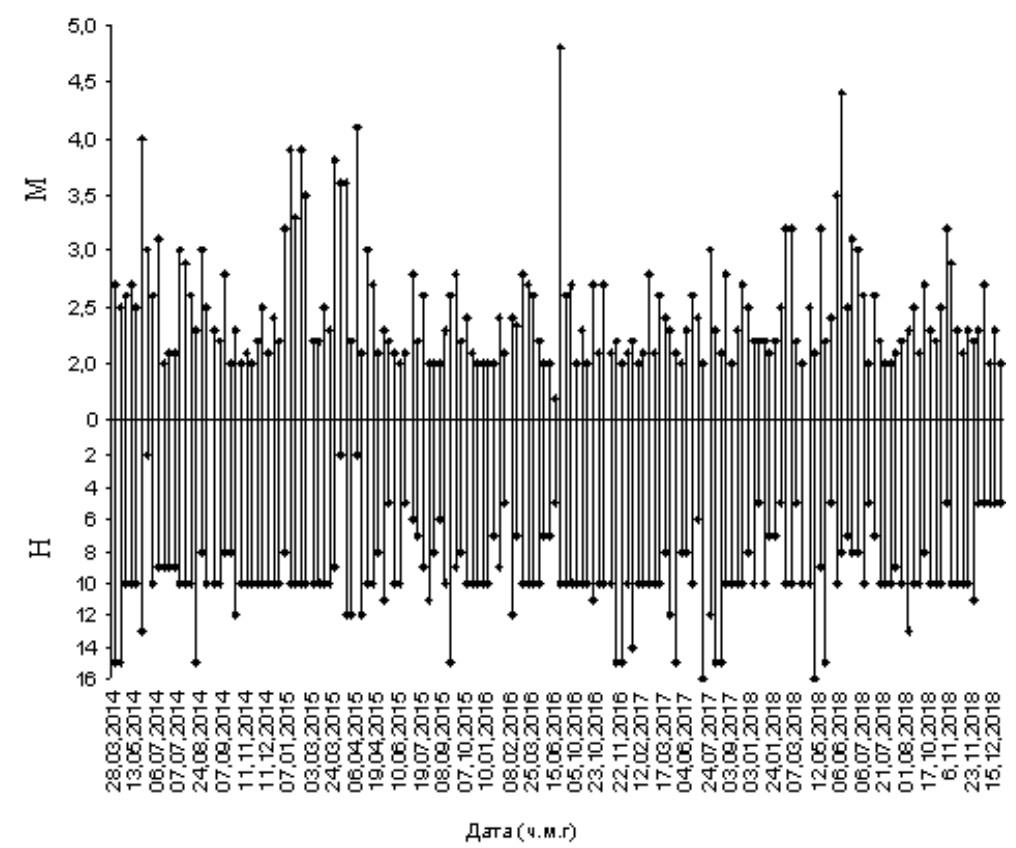

Figure 3. The date of earthquakes in magnitude and hypocenters /vertical lines/. 
To highlight the anomalous values of the chemical components of the geochemical field, the initial time series of the chemical element is being processed by subtracting seasonal changes, the root-mean-square value of the data, determining the deviations from the average value, dispersion and dispersion coefficient. The results of processing are correlated with seismicity as reflected in the example of changes in the total salinity of water ofborehole№I (Figure 4).

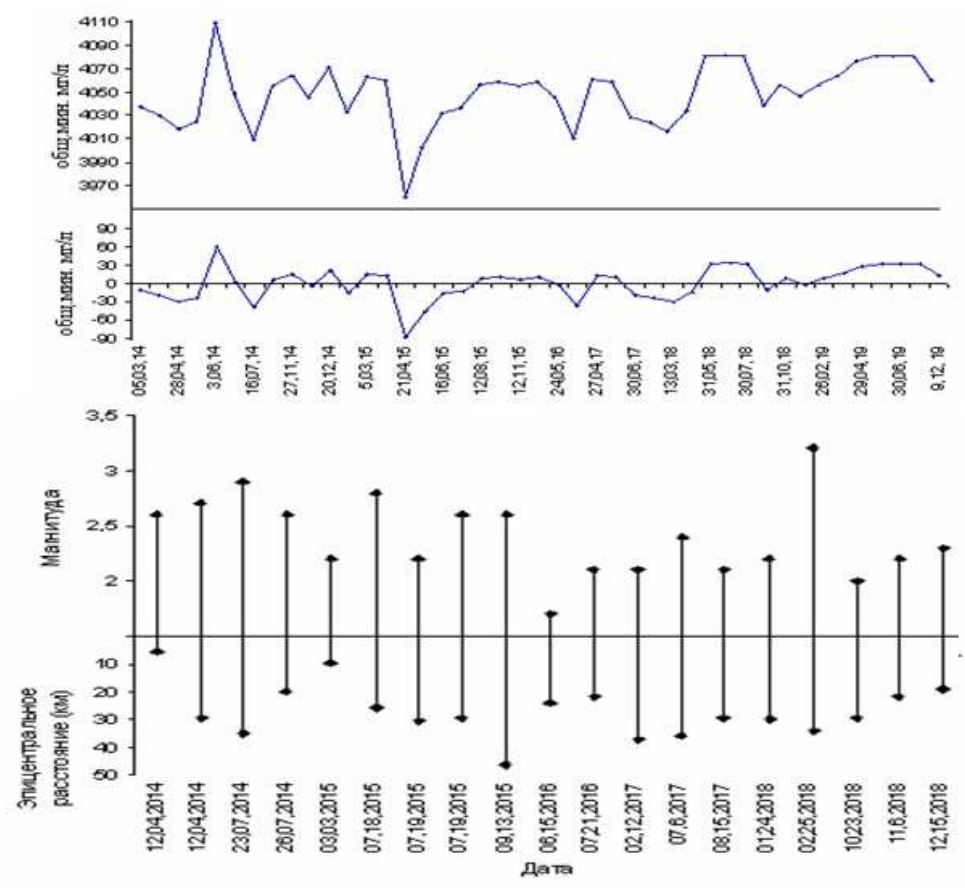

Figure 4. The variations in the total mineralization of the initial curve /first diagram/, the series after processing /second/, and the earthquakes with the corresponding magnitudes and epicentral distances /third diagram/.

\section{Results}

The available information on temporary variations of hydrodynamic and geochemical fields as a result of longterm regular observations reflects the stress-strain processes of the Earth's crust and the redistribution of tectonic stress fields. The influence of the seismic field of local weak crustal earthquakes $(\mathrm{M}=2.0-4.0)$ on the hydrogeodynamic and geochemical fields of the observation stations was determined. The estimated volumetric deformation [11] around the observation stations was determined based on the strength $(M>2)$ of earthquakes during the period considered. Furthermore, map of the stress-strain state of the Earth's crust of the territory of Armenia was built [12].

The map (Figure 5) reflects the stressed areas of the region, thus compression deformation occurs in the northern (Javakheti highlands) and central parts and on the southwestern border of Armenia. The map demonstrates a tensile strain along the eastern and western parts of the region. The type of deformation in the study was determined by calculating the Lode-Nadai coefficient, which was introduced into seismological practice [13]. Diagram of the change in the strain value (Figure 6) was developed for the same period as the map of deformation field (Figure 5) and indicates the activation of the geodynamic processes of the Earth's crust. The maximum value of the deformation was observed in 2015 $\left(10^{-7}\right)$, then it goes to the decrease of value inherent in tidal deformation $10^{-8}$.

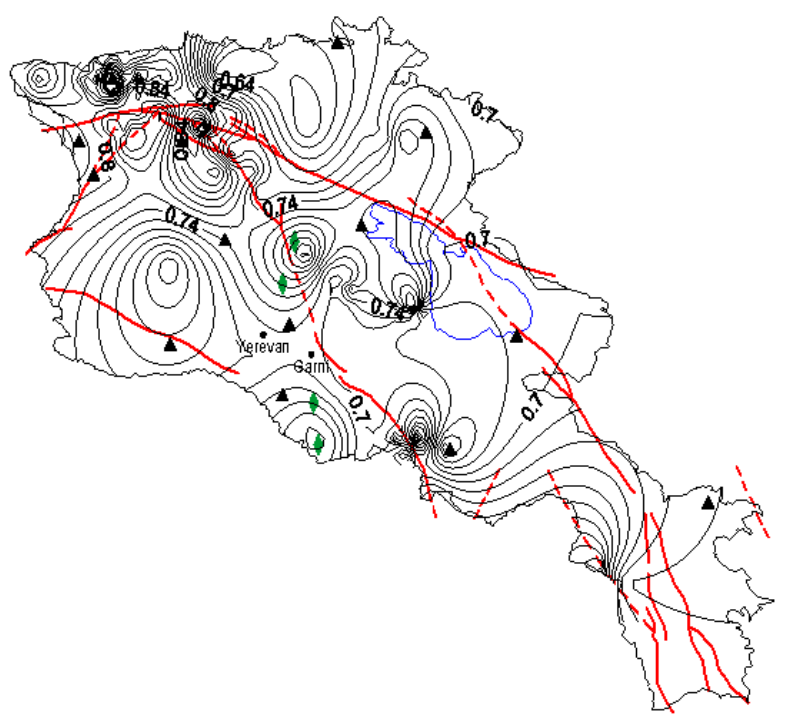

Figure 5. Map of stress-strain state of the Earth's crust of Armenia and diagram of changes in the annual averages of the estimated deformations of the Earth's crust.

Deformation structures are formed in the areas of increased seismicity. The epicenters are mainly timed to deep seismogenic faults: Bazum -Sevan, Garni and Yerevan. The magnitude of the volumetric deformation formed around the observation stations depends on the epicenter distance, magnitude and depth of the earthquakes. Seismicity 
parameters have been compared with the hydrogeochemical fields of the observation stations; as a result, testing of each observation point was carried out. The aim of testing is to identify the reaction of certain hydrogeochemical components to earthquakes. The anomalies of the identified chemical components observed after processing have values around three times higher than the dispersion values [14]. Thus, the calculated and received results are given in the tables where for each observation station those elements of the chemical composition of water are highlighted for which anomalies in the concentration of these elements with respect to the background value are obtained (Tables 1-3).

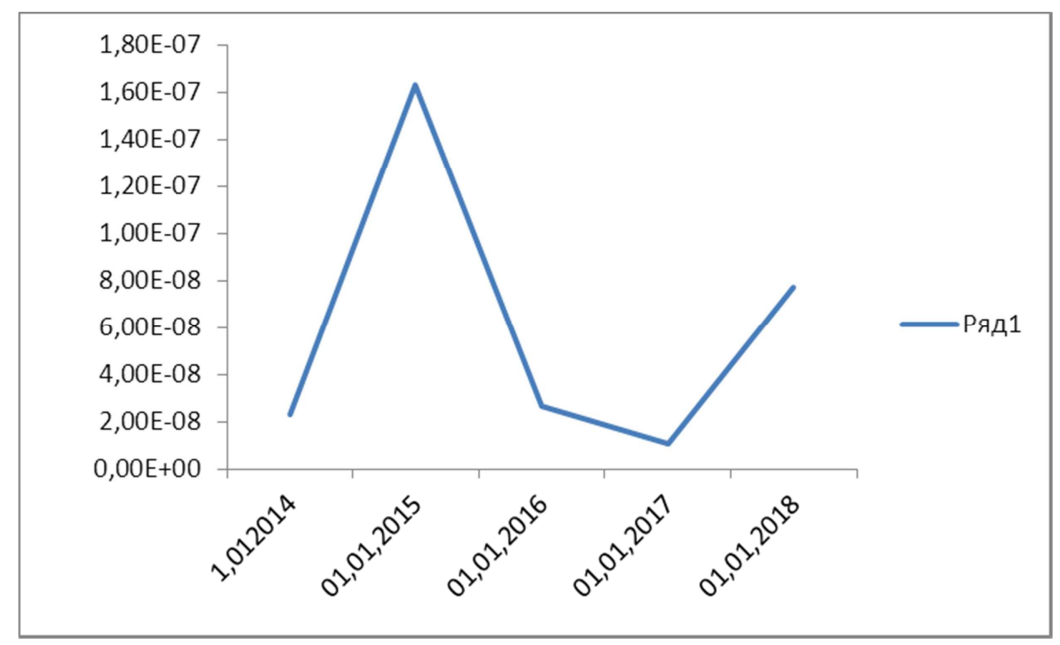

Figure 6. Diagram of changes in the annual averages of the estimated deformations of the Earth's crust.

Table 1. The Comparison of the Parametres of Seismic Effects with Revealed Effects of Hydrochemical Components for the first and second observation sites.

\begin{tabular}{|c|c|c|c|c|c|c|c|c|c|c|c|c|}
\hline \multicolumn{7}{|c|}{ Earthquake parameters } & \multicolumn{6}{|c|}{ Geochemical components of water } \\
\hline \multirow{2}{*}{\multicolumn{2}{|c|}{$\begin{array}{l}\text { Earthquake date, } \\
\text { observation stations }\end{array}$}} & \multirow{2}{*}{$\varphi$} & \multirow{2}{*}{$\lambda$} & \multirow{2}{*}{$\mathbf{M}^{*}$} & \multirow{2}{*}{$\mathbf{H}^{*}$} & \multirow{2}{*}{$\mathbf{D}^{*}$} & \multicolumn{2}{|l|}{$\mathrm{CO}_{2}$} & \multicolumn{2}{|c|}{$\mathrm{HCO}_{3}^{-}$} & \multicolumn{2}{|c|}{ Total water miner. } \\
\hline & & & & & & & $\delta^{*}$ & $\mathbf{A}^{*}$ & $\delta$ & $\mathbf{A}$ & $\delta$ & $\mathbf{A}$ \\
\hline \multirow{5}{*}{ I } & 18.06 .2009 & 40.23 & 44.82 & 4.1 & & 20 & 6 & $4 \delta$ & 6 & $4 \delta$ & 7 & $8 \delta$ \\
\hline & 19.10.2011 & 40.02 & 44.48 & 3.4 & 10 & 40 & 5 & $5 \delta$ & 6 & $8 \delta$ & & \\
\hline & 17.03 .2012 & 39.77 & 44.82 & 2.6 & 5 & 8 & & & & & 4 & $4 \delta$ \\
\hline & 12.04 .2014 & 39.79 & 44.8 & 2.6 & 10 & 5 & 7 & $8 \delta$ & 5 & $5 \delta$ & 5 & $6 \delta$ \\
\hline & 11.6 .2018 & 39.93 & 44.91 & 2.2 & 10 & 22 & 4 & $4 \delta$ & 10 & $6 \delta$ & 5 & $5 \delta$ \\
\hline \multirow{5}{*}{ II } & 16.03 .2010 & 39.93 & 44.72 & 2.1 & 5 & 1 & 8 & $12 \delta$ & 5 & $3 \delta$ & 6 & $5 \delta$ \\
\hline & 19.10 .2011 & 40.02 & 44.48 & 3.4 & 10 & 30 & 8 & $4 \delta$ & & & 6 & $6 \delta$ \\
\hline & 12.02 .2012 & 40 & 44.73 & 2.3 & 8 & 8 & 9 & $4 \delta$ & 6 & $5 \delta$ & 7 & $8 \delta$ \\
\hline & 03.03 .2015 & 39.36 & 44.72 & 2.2 & 10 & 6 & 5 & $3 \delta$ & 21 & $6 \delta$ & 12 & $6 \delta$ \\
\hline & 01.24 .2018 & 40.07 & 44.78 & 2.2 & 7 & 18 & 7 & $4 \delta$ & 7 & $7 \delta$ & 5 & $4 \delta$ \\
\hline
\end{tabular}

Table 2. The Comparison of the Parametres of Seismic Effects with Revealed Effects of Hydrochemical Components for the third observation site

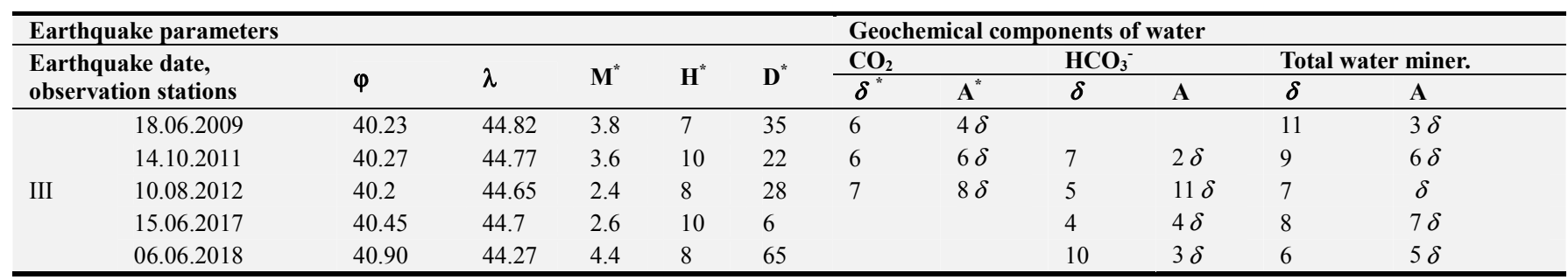

Table 3. The Comparison of the Parametres of Seismic Effects with Revealed Effects of Hydrochemical Components for the fourth observation site

\begin{tabular}{|c|c|c|c|c|c|c|c|c|c|c|c|c|}
\hline \multicolumn{7}{|c|}{ Earthquake parameters } & \multicolumn{6}{|c|}{ Geochemical components of water } \\
\hline \multirow{2}{*}{\multicolumn{2}{|c|}{$\begin{array}{l}\text { Earthquake date, } \\
\text { observation stations }\end{array}$}} & \multirow[b]{2}{*}{$\varphi$} & \multirow[b]{2}{*}{$\lambda$} & \multirow{2}{*}{$\mathbf{M}^{*}$} & \multirow{2}{*}{$\mathbf{H}^{*}$} & \multirow{2}{*}{$\mathbf{D}^{*}$} & \multirow{2}{*}{$\frac{\mathrm{Mg}^{+2}}{\delta^{*}}$} & \multicolumn{3}{|c|}{$\mathrm{CL}^{-}$} & \multicolumn{2}{|c|}{ Total water miner. } \\
\hline & & & & & & & & $\mathbf{A}^{*}$ & $\delta$ & $\mathbf{A}$ & $\delta$ & A \\
\hline \multirow{5}{*}{ IV } & 18.06 .2009 & 40.23 & 44.82 & 4.1 & 7 & 20 & 2 & $2 \delta$ & 7 & $3 \delta$ & 9 & $9 \delta$ \\
\hline & 14.10 .2011 & 40.3 & 44.66 & 3.6 & 10 & 8 & 3 & $2 \delta$ & 8 & $13 \delta$ & 12 & $1 \delta$ \\
\hline & 04.19 .2015 & 40.01 & 44.49 & 2.3 & 11 & 26 & 2 & $1 \delta$ & 3 & $2 \delta$ & 8 & $3 \delta$ \\
\hline & 06.06 .2018 & 40.90 & 44.27 & 4.4 & 8 & 74 & 4 & $2 \delta$ & 13 & $9 \delta$ & 4 & $1 \delta$ \\
\hline & 07.21 .2018 & 40.35 & 44.85 & 2 & 10 & 28 & 4 & $3 \delta$ & 13 & $9 \delta$ & 4 & $3 \delta$ \\
\hline
\end{tabular}

$M^{*}$-magnitude, $H^{*}$ - depth, $D^{*}$ - epicentral distance, $\delta^{*}$ - dispersion, $A^{*}$ - value of geochemical effect. 
As the tables 1-3 demonstrate, only in case of three components hydrogeochemical effects have been calculated before earthquakes according to the geochemical composition of water of each observation station. Figure 7 shows diagram of the hydrogeochemical effect, using the example of the values: CL- ion and total water mineralization of observation station№IV [15] (Table 3).

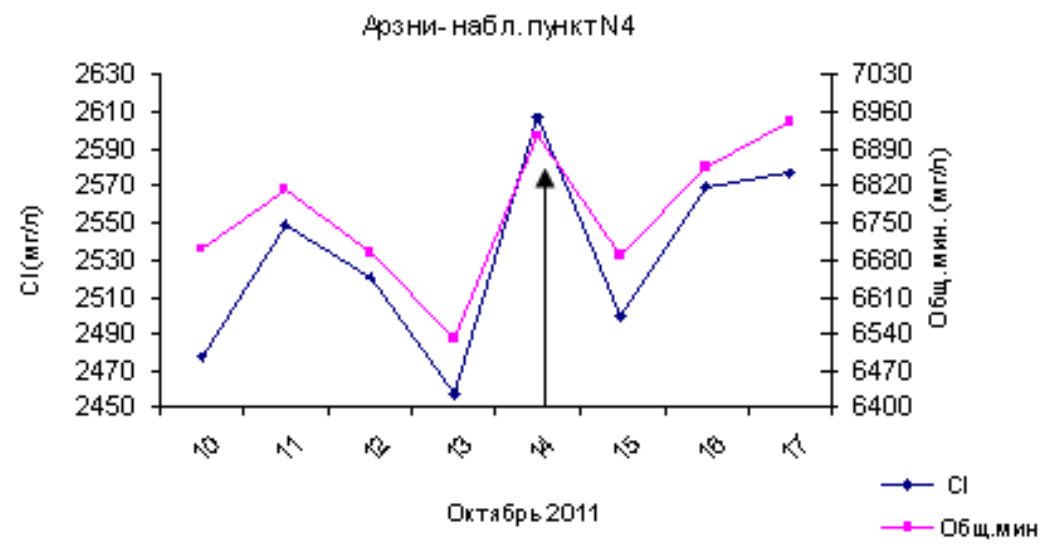

Figure 7. Diagram of variation of chemical components before earthquake: 14, 10, 11, M=3.6 (Table 3).

\section{Discussion}

A correlation method for processing the time series has been applied to study the hydrogeochemical effects. It was revealed that the correlation between the analyzed time series is destroyed before strong seismic events. Further studies in this direction would determine whether the resulting effect is predictive. It has been indicated that the usage of method of nonstationary parametre of flicker-noise spectroscopy according to the changes in the statistical structure of the time series, allows more formalized identification of characteristics of variations of hydrogeochemical indicators that are associated with strong seismic events in time. The characteristics of hydrochemical study of mineral water considered in this research is that they can differ in time and nature of occurrence depending on hydrogeological conditions, location and the intensity of earthquakes. The justifications of hydrochemical precursors of earthquakes presupposes the study of hydrogeochemical effects of monitoring observations during earthquake preparation.

\section{Conclusion}

The in formativeness of observation stations, the selection of the most reliable geochemical precursors of earthquakes, and the development of appropriate methods for analyzing and interpreting data are assessed.

Correlations between the parameters of seismic and geochemical fields are estimated.

Each observation point (I, II, III, IV) was tested according to the received abnormal values of the concentration of chemical elements inherent to the given hydrogeochemical observation station.

Hydrogeochemical method in combination with other methods can serve as an excellent precursor ofearthquake and other geodynamic processes of the earth's crust.

\section{References}

[1] I. G. Kissin "Fluids in the Earth's Crust, Geophysical and Tectonical Aspects". Journal "Nauka", 2009, pp 184-189.

[2] R. A. Pashayan, A. L. Ananyan. "The Characteristics of the Reaction of Certain Mineral Sources of Armenia on the Strong Earthquakes". Proceedings of NAS RA, Earth Sciences, 1994, LVI, N1-2, pp 113-118.

[3] V. A. Igumnov, Z. G. Stepanyan "Certain Hydrochemical Aspects of Spitak Earthquake" Proceedings of NAS RA, Earth Sciences, 1989, vol. 42, pp 24-33.

[4] R. A. Pashayan, L. V. Harutyunyan "Modern Changes of Geodynamics of the Earth's Crust of the Territory of Armenia" Reports of NAS RA, 2019, vol. 119, N3 pp 249-257.

[5] L. A. Hakhverdyan, R. A. Pashayan, L. V. Harutyunyan, "Connection between Variations of Stress-Strain State of the Earth's Crust and Seismic activity on the territory of Armenia" Reports of NAS RA, 2018, Vol. 118, N3, pp 260-267.

[6] Hydrogeology of USSR, Moscow. Journal 'Nedra'. vol. X1, 1968, p. 351.

[7] R. A. Pashayan "Mineral Water of Central Armenia", Lambert Academic Publishing, Russia, 2019, p 54.

[8] R. A. Pashayan, L. V. Harutyunyan "Geochemical Study of Seismotectonic Movements of the Earth's Crust of the Central Armenia" Reports of NAS RA, vol. 120 N3, pp 191-197.

[9] V. L. Barsukov "Geochemical Methods of Earthquake Prediction" Journal "Nauka", 1992, p 213.

[10] Yu. M. Khatkevich, G. V. Ryabinin "Hydrogeochemical Study at Kamchatka in connection with the Search of Earthqauke Prescursors". Volcanology and Seismology, 2006, N 4, pp 34-42.

[11] I. G. Dobrovolski, S. I. Zubkov, V. I. Myachkin. “On Assessment of the Size of Areas of Manifestation of Earthquake Precursors" vol. Modeling of Earthquake Precursors, Journal "Nauka", 1980, pp 7-43. 
[12] R. A. Pashayan, A. Z. Sargsyan "Hydrogeodeformational Characteristic of Earth's Crust of Armenia (2002-2004) ". Proceedings of NAS RA, Earth Science, LIX, № 2, 2006, pp 30-36.

[13] S. L. Yunga "On Mechanism of Deformation of Seismically Active Volume of Earth's Crust" Proceedings of AS SSSR. Earth Physics, 1979, № 10, pp 14-23.
[14] S. V. Grigoryan, R. A. Pashayan, L. V. Harutyunyan Hydrogeodynmaic and Geochemical Precursors of Earthqauke at the Territory of Armenia. Reports NAS RA. 2015. V. 115. № 1. C. $50-58$.

[15] G. V. Ryabinin, R. A. Pashayan, L. V. Harutyunyan "Changes in the Concentrations of Chloride Ion in the Mineral Waters of Central Armenia" NA RA Online journal of Natural Sciences 1 (28), 2017, pp 21-24. 